\title{
Methane matters
}

\author{
The Global Methane Pledge is a good start, but larger cuts in emissions are achievable with current technology. \\ More ambition is needed to help limit warming to $1.5^{\circ} \mathrm{C}$.
}

ollowing a year-long delay, leaders

from around the world met last month for the much anticipated 26th United Nations Climate Change Conference (COP26). The international community came together once more to discuss action on climate change during two weeks of negotiations, impassioned speeches and public protests. A number of new agreements were officially launched during the talks, including the first international agreement to limit global methane emissions. Over 100 countries have now signed the Global Methane Pledge ${ }^{1}$ that aims to reduce emissions by at least $30 \%$ before 2030. But to fully realize the potential climate benefits that methane cuts could offer, the target needs to be more ambitious, and must not distract from efforts to cut carbon dioxide emissions.

Methane has generally taken a backseat in climate mitigation discussions, given the primary importance of carbon dioxide. However, the impact of methane is by no means negligible, having contributed about one-third of the current anthropogenic greenhouse gas-driven warming ${ }^{2}$. With action on climate change becoming increasingly time sensitive, limiting methane offers an important opportunity to achieve rapid results.

Quick temperature benefits are possible thanks to the short atmospheric lifetime of methane. Unlike carbon dioxide, which remains in the atmosphere for centuries, methane lasts on average for just a decade. This means that if methane emissions were reduced, the atmospheric concentration would fall soon after, delivering some much-needed near-term mitigation. On top of this, reducing methane would also improve air quality and human health by curbing the formation of tropospheric ozone, an air pollutant with multiple harmful impacts ${ }^{3}$.

Substantial cuts in methane emissions are achievable with readily available technology, and at low cost ${ }^{4}$. There are a wide variety of anthropogenic methane

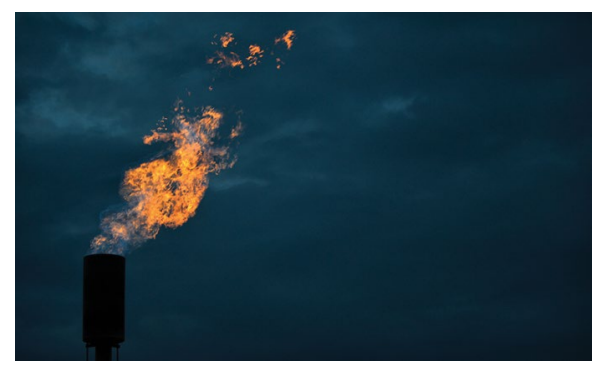

Credit: Carl Young / EyeEm / Getty Images

sources, including leaks from the oil and gas industry, the raising of livestock and the decomposition of waste in landfills. Simple strategies, such as plugging leaks from industry ${ }^{5}$, or giving cows a feed supplement ${ }^{6}$, could bring emissions down dramatically. It has been estimated that global methane emissions in 2030 could be reduced by $57 \%$ using available strategies and technology, and almost half of this could be achieved at no economic cost ${ }^{4}$. Implementing such measures could reduce global warming by around $0.25^{\circ} \mathrm{C}$ in 2050 , and $0.5^{\circ} \mathrm{C}$ by the end of the century $y^{4}$. In comparison, the Global Methane Pledge falls somewhat short. If fulfilled, the pledge is expected to save just $0.2^{\circ} \mathrm{C}$ by the end of the century - more ambitious targets than this are needed.

The speed and timing of emission reductions are critical to achieving the near-term benefits. Slow or delayed implementation could substantially reduce the mid-century temperature savings ${ }^{4}$, highlighting the importance of setting higher targets now. It is also crucial that action to address methane does not detrimentally impact efforts to tackle carbon dioxide emissions. Owing to the long atmospheric lifetime of carbon dioxide, any delay in cutting emissions will lock in more warming over the longer term. Action to address methane must be in addition to, not in place of, other vital climate measures.
Various other climate mitigation targets have emerged from COP26. Over 130 countries, representing $90 \%$ of the world's forests, have pledged ${ }^{7}$ to halt and reverse forest loss and land degradation by 2030 . Many countries also revised their Nationally Determined Contributions (NDCs), which outline their proposed actions to limit national greenhouse gas emissions. Optimistically assuming that all of the pledges and promises made at COP26 will be kept, early estimates suggest that this would limit global warming to $1.8^{\circ} \mathrm{C}$ by the end of the century ${ }^{8}$. However, on the basis of policies in place now, we are still on course for at least $2.6^{\circ} \mathrm{C}$ of warming. Although COP26 has delivered some much-needed progress, we remain well behind if we are to achieve the $1.5^{\circ} \mathrm{C}$ target set out in the Paris Agreement.

The Global Methane Pledge represents an important step in the right direction to help limit warming. However, there is room to go further, with technology available to bring bigger rewards, and several big emitters remaining absent from the agreement. Moving forwards, it is vital that governments around the world take action immediately to turn COP26 pledges into reality.

Published online: 3 December 2021 https://doi.org/10.1038/s41561-021-00875-1

References

1. Launch by United States, the European Union, and Partners of the Global Methane Pledge to Keep 1.5C Within Reach (European Commission, 2021); https://go.nature.com/30yThpT

2. IPCC Climate Change 2021: The Physical Science Basis (eds Masson-Delmotte, V. et al.) (Cambridge Univ. Press, in the press).

3. West, J. J. et al. Proc. Natl Acad. Sci. USA 103, 3988-3993 (2006)

4. Ocko, I. B. et al. Environ. Res. Lett. 16, 054042 (2021).

5. Nisbet, E. G. et al. Rev. Geophys. 58, e2019RG000675 (2020).

6. Hristov, A. N. et al. Proc. Natl Acad. Sci. USA 112, 10663-10668 (2015)

7. Glasgow Leaders' Declaration on Forests and Land Use (United Nations Climate Change, 2021); https://go.nature.com/ 3FmrE2i

8. Hausfather, Z. \& Forster, P. Analysis: do COP26 promises keep global warming below 2C? Carbon Brief (10 November 2021); https://go.nature.com/3Cn3pPK 